\title{
Spotlights
}

\author{
Sarah Berry ${ }^{1}$
}

Published online: 23 June 2017

(C) Springer Science+Business Media, LLC 2017

1. "No one is born knowing how to bring up the topic of death with a patient, to suspect child abuse when a child is admitted with a broken bone, to expect the difficulties that arise between the medical system and patient care, or to question whether a deeper issue is hiding beneath a physical ailment. My Medical Humanities training at Baylor University exposed me to these topics in the form of discussions, readings, research, and shadowing experiences, providing a platform for me to digest these matters and reflect on the influences they will have on my career. The understanding that resulted from this process directed my decision to attend an osteopathic medical school and also shaped my thoughts on which branch of medicine to pursue."

\section{Youjin $\mathrm{Na}$}

Baylor University 2015 (Medical Humanities minor)

2. "'Death and Dying' is a very popular course for most pre-med students. The professors taught us how to accept the inevitability of death and how to empathize with our patients in the process of dying. In medical school we spent two weeks on the subject, whereas at Baylor University we spent an entire semester on death and dying."

\section{Roshan Patel}

Baylor University 2013 (Medical Humanities major [BA])

Ross University School of Medicine 2018

3. "Compartmentalization offers a way of avoiding the questions that ought to keep us up at night by asking ones that are more digestible. It is much easier to ask, 'What stage of cancer is this patient in?' than 'How can we provide quality, comfortable end of life treatment for the terminal cancer patient?' I argue that we have a duty not

Sarah Berry

sarahberryphd@gmail.com

1 Humanities Division, Centre College, Danville, KY 40422, USA 
only as medical professionals but also as human beings to consider both questions with equal and utmost diligence. Studying as a Medical Humanities major helped me to examine and explore the depths of medical philosophy as rigorously as I was examining the sciences. Doing so opened my eyes to how ill-equipped I was to deal with the lingering questions and challenged me to press on in the direction of medical ethics and philosophy."

Sean Browning

Baylor University 2016 (Medical Humanities major [BA])

London School of Hygiene and Tropical Medicine, MSc. Epidemiology, 2017

4. "One of the most important things I learned (probably in my very first class in the minor, 'Introduction to Social Health Care') is that you cannot attempt to explain human suffering because in reality human suffering demands silence and respect. All this time I was looking at illness and disease as something I needed to 'cure' or 'fix.' I failed to recognize the most important job of a healthcare provider - to accompany someone in suffering. It is a remarkable experience when a person who has never had chronic illness has the opportunity to read and to begin to understand - to a certain extent of course - what it is like to live a day in the life of someone who has had chronic illness since birth. Understanding is what leads to comfort and humane treatment, especially in the absence of cure. Not everything can be solved with medication and IVs, and that is okay. The real challenge comes in recognizing another person's situation by looking beneath the surface of a disease."

Gabriella Vazquez

Boston College 2016 (Medical Humanities minor)

5. "The interdisciplinary nature of my Health Humanities coursework pulled together biology, sociology, gender studies, narrative medicine, speculative fiction, bioethics, anthropology, disability studies, and ethnicity and race studies. It allowed me to see that healthcare is greater than a checklist of symptoms and possible outcomes. Healthcare must see humanity in a way that involves the scaffolding of peoples' identity and that appreciates the amalgam of their individuality. After the class experience, I ensure my conversations with patients take into account their experience, their voice, and their narrative. Care is no longer something I perform; it is a mindset in which I actively acknowledge the humanity and the value of the life before me. It is imperative that I give each patient the opportunity to have agency in determining their care and in their decision to include me in their health narrative."

Michael Price

Columbia University 2017 (Ethnicity and Race Studies, Pre-Health Track)

Community-Based Emergency Caregiver volunteer, United Rescue

6. "After graduating in 2013, I moved to Los Angeles to serve as a long-term AmeriCorps volunteer. I worked as a Case Manager at a shelter for men experiencing homelessness. Perhaps there was no better way to prepare for this role than to be able to synthesize narratives. I connected 
with my clients. There were 65 residents in the shelter, and there were 65 different circumstances that brought them there."

Hannah Petcovic

Hiram College 2013 (Biomedical Humanities major [BA])

Accelerated Bachelors of Science in Nursing, College of Nursing, Kent State University 2017

7. "My Biomedical Humanities courses taught me to dig deeper and to question everything. They also taught me that the answer may not be as strong as the question."

Allison Fox

Hiram College 2014 (Biomedical Humanities major [BA])

Masters in Education, Kent State University 2018

8. "As a current Nursing student and future Advanced Practice Nurse, I am dealing with things that are far beyond my scope of personal experience as a 22-year-old. Illness, disability, and death are enormous life events to face with someone. These are not experiences that I want to attempt to explore for the first time at a patient's bedside. If I hadn't had a safe place to discuss their meaning and gravity with instructors and peers, I'm not sure how I could have been so present and open to patients during their times of emotional vulnerability while facing illness."

Danielle Lenz

Indiana University-Purdue University Indianapolis 2015 (Medical Humanities and Health Studies major [BA])

Vanderbilt University MSN in Advanced Practice Psychiatric Mental Health Nursing 2017

9. "[T]he Medical Humanities and Health Studies Program has helped me to put the isolated and frenetic world of medical school in perspective."

Peter Coleman

Indiana University-Purdue University Indianapolis 2014 (Medical Humanities and Health Studies minor)

Indiana University School of Medicine 2018

10. "As I move forward in my pursuit to become a Registered Dietitian, I undoubtedly will continue to draw upon the insight garnered from my education in Health Humanities. 'Biomedical Ethics' introduced me not only to the plethora of dilemmas and difficult-toanswer questions in medicine but more importantly, gave me a systematic way to think about them. As students, we were responsible for working through a case study and presenting it to the class. Feedback and questions from peers required the presenter to be prepared to thoroughly defend his or her plan of action. This opportunity gave me a taste of how I would handle a similar situation as a healthcare professional. The perspectives I gained from my Health Humanities education as an undergrad ultimately helped me take a step back and ask 
myself what I am most passionate about, and in turn, how I can make the most significant impact on others in my career."

Holly Anderson

Oregon State University 2014 (Biology major [BS]; Chemistry and Spanish minors)

Graduate Coordinated Program in Dietetics, University of Washington 2018

11. "One of the initial benefits I noticed in my Medical Humanities classes was the change of pace I experienced. We spend so much time developing multiple-choice test taking skills in our science curriculum, but I have yet to encounter a patient who presented their illness in that format. I was fortunate that my humanities classes developed my analysis skills and taught me how to form an educated opinion. I was delighted when I realized that the diagnostic process is strikingly similar to writing a paper. You analyze stories in the form of patient and family histories, discuss these stories, sort through medical literature and then sit down and form an educated opinion about what is going on. With the electronic medical records we even get to harken back to our college days and type a ten- to twelve-page paper explaining our opinion in the form of an H\&P. Given the overlap of skills involved, I truly believe that my ability to take a history and efficiently form a differential diagnosis was facilitated by my Medical Humanities courses."

\section{Konstantin German, MD}

Saint Louis University 2012 (Certificate in Medical Humanities)

Saint Louis University School of Medicine 2016

12. "I was at my first clinic-site visit, prepared to be a bystander, shadowing and absorbing information when I could. I was told to go into a patient's room with a nurse and take vitals. It became obvious, however, that the patient was distressed. She had tissues with her, and her eyes, red from tears, revealed sorrow. The nurse and I comforted the patient, who soon told us that her daughter had recently died. I have never experienced this type of loss, and I could not imagine the hurt she was feeling. I chose to pursue a minor in Medical Humanities to prepare myself for the obligations of medicine that go far beyond scientific knowledge and diagnostic acumen; they also involve compassion, integrity, and beneficence. Thus, when I was presented with the grieving patient, I felt prepared, remembering all of the in-class discussions and dialogues about suffering, about Atul Gawande's Being Mortal, about placing the patient first. I sat down in a chair next to the patient and for the next twenty minutes I talked with her about her daughter. She was such a loving mother, and I think being able to talk about her daughter and share her story was healing, in a way."

Henry Ideker

Saint Louis University 2015 (Medical Humanities minor)

University of Texas Medical Branch School of Medicine 2019

13. "Appropriate patient treatment is about more than just medical science. It is also about personal interaction with patients. It is important to learn about empathy towards patients' concerns, various cultures, and religious beliefs early so these skills can become habits when interacting with patients." 
Sarah Panone

University of Michigan-Ann Arbor 2019 (prospective Movement Science major, School of Kinesiology)

14. "What I did not expect from this program was the complete shift in my perspective on science and healthcare. While my science studies gave a wealth of facts, information, diagrams and terms, Health Humanities gave me empathy and a greater understanding of the narrative of scientific history."

Kassandra Reyes

University of Texas at Dallas 2016 (Medical and Scientific Humanities minor)

15. "Health Humanities has instilled in me a lifelong desire to actively make time for art in my life."

Ayesha Tasneem

University of Toronto Scarborough 2017 (Neuroscience and Molecular Biology major [BS])

16. "I have been drawn to consider the legacy of western imperialism in medicine, the role of physician as storyteller, and the limitations of goodwill and beneficence. Though many of the analyses and texts we studied have critiqued biomedicine, these courses have inspired me to reflect on my own preconceptions and ideas about what it means to be 'a good doctor.' While it will be years before I can put a band-aid on a patient, much less conduct a differential diagnosis, I am keenly aware of the way that the Medical Humanities program has led to evaluating and beginning to think about a standard of care more qualitative perhaps than an organic chemistry final exam but no less valuable."

Susannah Boyed

Virginia Commonwealth University 2017 (Interdisciplinary Studies major)

17. "As an art student, and more particularly as a dancer and choreographer, interacting with bodies in space is more than a physical relationship. Through studies of history, science, narrative, and philosophy, Medical Humanities has painted for me a holistic picture of the human body."

Taylor-Leigh Adams

Virginia Commonwealth University 2017 (Dance and Choreography major, Medical Humanities minor) 